EGU2020-9727

https://doi.org/10.5194/egusphere-egu2020-9727

EGU General Assembly 2020

(c) Author(s) 2020. This work is distributed under

the Creative Commons Attribution 4.0 License.

\title{
The opening of the Tyrrhenian basin and the Apennine chain formation in the kinematic context of Africa - Europe collision
}

\author{
Eugenio Turco ${ }^{1}$, Chiara Macchiavelli ${ }^{2}$, Pietro Paolo Pierantoni ${ }^{1}$, Giulia Penza ${ }^{1}$, and Antonio \\ Schettino ${ }^{1}$ \\ ${ }^{1}$ School of Science and Technology- Geology Division, University of Camerino, CAMERINO (MC) - ITALY \\ ${ }^{2}$ Institute of Earth Sciences Jaume Almera, Structure and Dynamics of the Earth, Group of Dynamics of the Lithosphere, \\ BARCELONA - SPAIN
}

The Africa Europe collision, which produces the formation of the Alpine arc, in the Mediterranean area is accompanied by passive subduction processes, resulting from the sinking of the remnant Alpine Tethys and the Ionian lithosphere, and from the fragmentation of the Adriatic plate. In this complex deformation, back-arc basins (Alboran, Balearic, Tyrrhenian and Hellenic) and circum Mediterranean mountain ranges are formed.

In this work we focus our attention on the opening of the Tyrrhenian basin and the contemporary formation of the Apennine chain.

In order to describe the evolution of the geodynamic processes that guided the formation of the Tyrrhenian basin and the Apennine chain we used the plate kinematics technique. Through careful observation of the regional structures we have divided the area of the Apennine Chain and the Tyrrhenian basin into polygons (crustal blocks or microplates) distinguished on the basis of the direction of the Tyrrhenian extension. The boundary between the polygons has been placed coinciding with the large structures that characterize the Tyrrhenian-Apennine area. The rotation poles of the individual polygons, in the frame of reference of the Sardo-Corso block, are based on the Tyrrhenian extension directions that characterize them. The velocity ratio between the polygons was determined by the slip vector of the structure (plate boundary) that separates them. To determine the rotation time of the polygons we used the stratigraphic records of the syn-rift sequences, while the rotation angle of the polygons is obtained comparing the crustal balance with the speed ratios.

Finally, the kinematic framework obtained, included in the global rotation model, allowed us to reconstruct the tectonic evolution of the central Mediterranean during the opening of the Tyrrhenian basin.

Key Words: Tyrrhenian-Apennine System, Non-rigid plate kinematics. 